\title{
A abordagem dos maus-tratos contra a criança e 0 adolescente em uma unidade pública de saúde
}

\author{
The approach to bad treatment against children \\ and teenagers in a public health-care unit
}

Romeu Gomes 1

$M$ aria de Fátima Pinheiro

da Silva Junqueira 1

Cristiani de Oliveira Silva 1

Washington Leite Junger 1

\footnotetext{
1 Pós-Graduação em Saúde da Criança e da Mulher do Instituto Fernandes Figueira da Fundação Oswaldo Cruz. Av. Rui Barbosa 716, Flamengo, 22250-020, Rio de Janeiro RJ. romeu@iff.fiocruz.br
}

\begin{abstract}
The study is part of a broader research on the approach to cases of maltreatment committed against children and teenagers. The objective to analyze the perception of the professionals of the public system in relation to the approach conducted in the above-mentioned cases. The methodological is based on a case study under a social research of qualitative approach by means of the half-structured interview technique. The field of research is the Insti tuto Fernandes Fi gueira at Fundação O swaldo Cruz. The treatment of the data is based on the principles of the content analysis. Among the results, we set special attention to the fact that maltreatment sometimes is visible for identification by the professionals and sometimes it becomes invisible in its attendance. Alongsi de this, we have verified the perception of the professionals oscillating between belief and incredulity in what concerns the solving of the cases. In terms of conclusion, it stands out that, in relation to the complexity of the violence committed against children and teenagers, questions like professional capacity, the planning of integrated actions and the participation of professionals in public actions, must be taken into consideration, looking for a better approach of maltreatment cases.
\end{abstract}

Key words Approach, Health-care professionals, M altreatment, Children, Teenagers
Resumo Este estudo integra uma pesquisa sobre a abordagem dos casos de maus- tratos cometidos contra crianças e adolescentes. 0 objetivo é analisar a percepção dos profissionais de saú de da rede pública frente à abordagem realizada nestes casos. 0 desenho metodológico baseia-se em estudo de caso, numa abordagem qualitativa de pesquisa social, através da técnica de entrevista semi-estruturada. 0 campo de estudo é o Instituto Fernandes Figueira da Fundação O swaldo Cruz. 0 tratamento dos dados baseia-se em princípios do método de análise de conteúdo. Dentre os resultados, destaca-se que os maus- tratos ora assumem uma visibilidade na identificação por parte dos profissi onais, ora ficam invisíveis em seu atendimento. Junto a isso, verifica-se que a percepção dos profissionais oscila entre a crença e a descrença na resolubilidade dos casos. Em termos de conclusão, ressalta-se que, frenteà complexidade da violência cometida contra crianças e adol escentes, questões como capacitação profissional, planejamento de ações integradas e parti cipação dos profissionais em ações públicas devem ser equacionadas, visando a uma melhor abordagem desses casos.

Palavras-chave Abordagem, Profissionais de saúde, M aus- tratos, Crianças, Adolescentes 


\section{Introdução}

Os maus-tratos cometidos contra a criança e o adolescente podem ser praticados pela omissão, pela supressão ou transgressão dos seus direitos, definidos por conven ções legais ou normas culturais (SBP/Fiocruz/MJ, 2001).

Esses maus-tratos são tão relevantes que existem mecanismos legais e instituições que se voltam para a prevenção e para a intervenção frente à sua ocorrência. No Brasil, desde 1990, há uma regulamentação específica sobre 0 assunto, no Estatuto da Criança e do Adolescente - ECA (Brasil, 1997). N essa legislação, se destaca o papel dos profissionais de saúde e de educação quanto à identificação e notificação de casos de violência.

Deslandes (1994), referindo-se à obrigatoriedade da notificação prevista no ECA, observa que a definição a priori das normas legais não foi precedida nem acompanhada de normas técnicas e éticas geradas pelos e para os profissionais de saúde. No entanto, atualmente, essa observação pode ser relativizada, uma vez que já há documentos que regulamentam, de uma certa forma, o procedimento a ser tomado pelo profissional de saúde. A exemplo desses documentos, pode ser citado o Guia de atuação frente a maus-tratos na infância ena adolescência (SBP/ Fiocruz/M J, 2001).

Embora tenha havido um avanço nesse campo, pode-se considerar que, entre tal preceito legal do ECA e a prática desses profissionais, há ainda uma distância a ser vencida, uma vez que nem sempre tais profissionais se sentem preparados para assumir tais atribuições.

M ediante a complexidade dos maus-tratos cometidos contra a infância e a adolescência, a abordagem efetuada dentro de uma instituição de saúde merece um estudo mais detal hado. Cabe ressaltar que, neste trabalho, a abordagem refere-se aos procedimentos adotad os frente a tais situações. Torna-se relevante, então, saber quais são os critérios adotados pela equipe de saúde para o levantamento de suspeitas a esse respeito e os encaminhamentos realizados.

Essa discussão deve ser ancorada nas experiências dos profissionais de saúde no trato com a temática em questão. Nesse sentido, a proposta deste estudo é justamente analisar a percepção de profissionais de uma unidade pública de saúde sobre a abordagem dos casos de maus-tratos cometidos contra a criança e o adolescente visando identificar critérios, limites e possíveis lacunas em tal abordagem.

\section{Metodologia}

Este trabalho integra um projeto de pesquisa mais amplo que procura discutir a abordagem dos profissionais de saúde de uma instituição pública frente aos casos de maus-tratos cometidos contra crianças e adolescentes. Em busca de uma maior visibilidade de tal abordagem, 0 trabalho desenha-se em torno de dois eixos: a) estudo das notificações de maus-tratos e seus respectivos prontuários; e b) análise de entrevistas de profissionais de saúde. N este trabaIho, focaliza-se apenas o último eixo, uma vez que se busca a análise da percepção dos profissionais acerca do assunto. 0 referido projeto foi aprovado pelo Comitê de Ética em Pesquisa com Seres Humanos do Instituto Fernandes Figueira (IFF) da Fundação Oswaldo Cruz (Fiocruz).

0 desenho metodológico baseia-se num estudo de caso, na perspectiva das ciências sociais, que, de um lado, procura compreender a dinâmica de um grupo, uma instituição ou um conjunto de interações sociais e, de outro, busca o desenvolvimento de considerações teóricas mais amplas acerca das estruturas sociais (Becker, 1993). N este estudo, focaliza-se a abordagem qualitativa no sentido de buscar uma compreensão mais ampla da realidade estudada ( $\mathrm{M} \mathrm{i-}$ nayo, 1992).

0 trabalho de campo, desenvolvido no pe ríodo de março de 1999 a julho de 2000, ocorreu no IFF/Fiocruz, que é composto, dentre outros setores, de um hospital da rede pública considerado como referência no que diz respeito à saúde materno-infantil. É uma unidade que não possui emergência, sendo seus atendimentos efetuados nos ambulatórios e nas enfermarias (Pediatria, Ginecologia e O bstetrícia).

Os sujeitos do estudo foram selecionados a partir dos seguintes critérios: ser profissional de nível superior; consentir em participar do estudo; atuar na instituição há mais de um ano e prestar atendimento a crianças e adolescentes nos ambulatórios e/ ou enfermarias. Em termos de número de sujeitos a serem considerados, por se tratar de um estudo qualitativo, a amostra foi ampliada até que se tivesse um quadro de análise suficientemente adequado a uma discussão aprofundada (M inayo, 1992).

A partir desses critérios, foram contemplados dezessete profissionais de saúde, sendo oito médicos, dois assistentes sociais, quatro enfermeiras etrês psicólogas. Do conjunto dos entrevistados, treze eram mulheres e quatro ho- 
mens. Com exceção de um profissional, que possuía um ano de experiência na instituição, todos nela trabal havam, pelo menos, há mais de cinco anos. Os nomes dos entrevistados foram substituídos para assegurar o seu anonimato. No sentido de facilitar a leitura, essa substituição foi feita de forma que a primeira letra indicasse a categoria profissional. Assim, os nomes fictícios iniciados pela letra $M$ foram utilizados para médicos, os iniciados com $E$ para enfermeiros, com A para assistentes sociais e $\mathrm{P}$ para psicólogos.

0 instrumento de investigação analisado neste trabalho foi a entrevista semi-estruturada, que procura combinar perguntas fechadas e abertas (M inayo, 1992). 0 roteiro dessa técnica contemplou os seguintes aspectos: a) critérios de identificação de casos de maus-tratos; b) procedimentos adotados; c) limites da atuação dos profissionais; d) lacunas existentes no atendimento e acompanhamento dos casos; e e) origens e possíveis conseqüências dessas lacunas.

A análise baseou-se na adaptação de princípios da técnica de análise de conteúdo, modalidade temática (Bardin, 1979; M inayo, 1992). No tratamento dos dados, procurou-se identificar os núcleos dos sentidos expressos nos registros, bem como, através de inferência, descobrir o que está por trás dos conteúdos manifestos, indo além das aparências do que está sendo comunicado (Gomes, 2001).

A trajetória da análise das entrevistas seguiu as seguintes etapas: a) compreensão geral dos depoimentos; b) identificação das idéias centrais (núcleos de sentido) dos materiais analisados por questão e por categoria de profissional; c) confronto entre os diferentes núcleos de sentido presentes no corpus de análise para se buscar temáticas mais amplas ou eixos estruturantes das falas; d) discussão dos resultados a partir de temáticas.

\section{Resultados do estudo}

A análise dos diferentes núcleos de sentido presentes nas respostas dos profissionais de saúde apontou para temáticas em torno das quais é possível discutir as percepções desses profissionais acerca da abordagem dos casos de violência contra a criança e 0 adolescente. Essas temáticas foram denominadas da seguinte forma: 0 visível e o invisível da violência ea crença ea descrença na resolubilidade dos casos de maus-tratos. $\mathrm{N}$ a primeira temática incluem-se os conceitos, as idéias e os critérios para se identificar e abordar os maus-tratos, enquanto a segunda traz a percepção dos profissionais tanto em relação aos seus limites de encaminhamento quanto às crenças e descrenças sobre os desfechos dados a esses casos.

\section{0 visível e o invisível da violência}

A atitude dos profissionais frente à abordagem dos maus-tratos cometidos contra a criança e 0 adolescente se encontra intimamente relacionada com a visibilidade ou não que o problema assume em seu cotidiano. A reflexão sobre os conceitos dos diferentes tipos de maus-tratos e as idéias a eles associadas contribuem para se entender os possíveis encaminhamentos que esses profissionais dão a tais casos quando identificáveis. Assim, a efetivação de um atendimento depende da possibilidade de ser capaz de identificar a presença ou a suspeita da violência nos diferentes casos atendidos. Por outro lado, ter ou não visibilidade depende, dentre outros aspectos, da escuta e do ol har ampliados que o profissional consegue imprimir em seu atendimento.

A negligência, entendida como omissão em termos de cuidados básicos por parte do responsável pela criança ou adolescente (SBP/Fiocruz/MJ, 2001), nas falas dos entrevistados, oscila entre os aspectos visível e invisível da violência, o que acaba por originar dúvidas em sua identificação. Ela se destaca em todos os depoimentos de todas as categorias profissionais. Diferentes situações caracterizam a negligência: 0 fato de o responsável não visitar no hospital [a criança], de não acompanhar quando vai para casa (Paola); situações em que a criança é deixada em casa sozinha e se acidenta (M eireles); crianças que aparecem malcuidadas, com marcas de impetigo [...] maltrajadas ( $\mathrm{M}$ agno) e os pais, de forma discrepante, são bem-cuidados; criança desnutrida [...] em péssimas condi ções higiênicas (Élida); a mãe não segue [ o tratamento], ou então ela está sonegando alguma informação (Marina).

Paralelamente ao fato de se constatar o abandono ou o estado em que a criança se encontra, há um outro indicador de negligência para os profissionais: a família [...] não leva, não vai dar a vacina (Amália).

Contrapondo a visibilidade dos critérios de diagnóstico apontados, a negligência também traz um aspecto invisível. Essa invisibilidade se 
traduz, principalmente na fala das assistentes sociais, pelo fato denem sempre ser possível diferenciar o queéa negligência pura esimplesmente [de] uma negligência por falta de condições de vida, [porque há] os abandonos e os abandonos [e] isso não está escrito no papel (Amália). 0 lado não tangível da negligência também se traduz quando um profissional utiliza uma expressão física, logo visível, para alertar sobre as suas graves conseqüências: 0 abandono eu acho é, como tivesse uma pancada (Ednéa).

Ainda sobre a invisibilidade que a negligência assume, ressalta-se o fato de alguns profissionais, inicialmente, estabelecerem uma diferença entre ela e os chamados maus-tratos. Assim, um profissional, num primeiro momento, faz uma categorização excludente quando diz que a negligência infantil é bem mais freqüente do que os maus-tratos propriamente ditos [ e em seguida arremata] que [a negligência] é um ato, um tipo de maus-tratos (M aurílio). Em outra entrevista se menciona aqueles maus-tratos e aquelas negligências (Amália), como se fossem coisas diferentes. Já, em outro depoimento, a exclusão é clara: violência que eu estou chamando seria ou violência sexual, ou violência física (Paola). Por último, há um depoimento que inclui a negligência nos maus- tratos sob certas condições, ao dizer que quando as mães abandonam [...] deixam de tratar [estão] maltratando de uma certa forma (Eva).

Nas falas dos atores sociais estudados, independentemente de sua catego ria profissional, os maus-tratos físicos, concebidos como uso intencional e não-acidental de força física para danificar ou destruir (SBP/Fiocruz/MJ, 2001), constituem a faceta mais visível da violência cometida contra crianças e adolescentes. Eles são pouco definidos pelos profissionais talvez pelo fato de o termo ser auto-explicativo, ou seja, são resultados de ações de deixar marcas visíveis (Ednéa). Um médico traz a denominação de violência ativa ( $M$ agno), para falar de agressão física cometida contra a criança, em oposição à omissão que se caracteriza pela ausência de uma ação.

Os sentidos atribuídos a esses maus-tratos são mais bem compreendidos a partir dos critérios apontados pelos profissionais, principalmente os médicos e as enfermeiras, para a sua identificação. Assim, os maus-tratos físicos são possivelmente diagnosticados quando os profissionais encontram criança com fraturas, muito pequenininha (Eva); fraturas, com traumas de crânio, com sinais de queimaduras de cigarro [ vis- tos ou demarcados por] exames clínicos e alguns tipos de exames radiológicos (M aurílio); mães [que] batem nas crianças, até mesmo quando elas estão aqui internadas (Ednéa); lactente até, criança atéquenão teria por queseacidentar ( $M$ eireles); criança [que] foi queimada pela mãe; mãe [que] jogou a criança na água fervendo no banho, ou jogou a chaleira deágua (M arina).

Por outro lado, a preocupação com os maustratos físicos não pode ser reduzida à constatação das marcas inscritas no corpo. Um caso de uma criança citado por alguns profissionais é bastante elucidativo para o alerta de se ampliar 0 olhar sobre os sinais físicos. Era um bebê de seis ou sete meses que foi internado cheio de hematomas, [foi o] pai que trouxe a criança, não veio com a mãe [e] a primeira hipótese foi de agressão (M arina). Entretanto esse bebê apresentava uma sintomatologia de uma doença (Amália), que fazia com que houvesse manchas roxas pe lo corpo. Segundo uma assistente social da equipe o profissional médico em geral, el es julgam pela apresentação, pela aparência que a criança tem (Amália). Cabe ressaltar que, além das marcas roxas, o fato de a criança ter sido trazida pelo pai e não pela mãe, visto que esta não estava bem emocionalmente ( $M$ arina), reforçou as suspeitas da equipe apontando para um preconceito [...] porque normalmente quando a criança tem algum quadro grave quem vem é a mãe [e para um] pré julgamento [desta família] (M arina). Esse caso remete à necessidade de não se deter apenas às marcas do corpo para diagnosticar os maus-tratos.

Em relação ao abuso sexual, visto como ato ou jogo sexual cujo agressor está em estágio psicossexual superior ao da vítima (SBP/Fiocruz/MJ, 2001), observa-se uma certa visibilidade de sua ocorrência a partir de marcas corporais, ou seja, patologias ginecológicas [...] corrimentos suspeitos [...] lesões suspeitas tipo condiloma [...] rotura himenal [...] trauma vaginal (Maíra) e uma DST em criança (Amanda) que podem apontar para a violência sexual.

Junto a esses sinais, há uma certa invisibilidade porque nem sempre esse tipo de abuso se evidencia através de marcas físicas. Assim, fazse necessário observar a reação da criança [...] os retraimentos que a criança apresenta para falar, na mesa do exame [...] a queixa propriamente dita [...] a história que a acompanhante conta [...] a maneira como a criança conta a história (M aíra). No caso de adolescentes grávidas, percebe-se esse tipo de violência, através do relato (Moacir); quando existe uma diferença muito 
grande de idade entre a adolescente e o pai da criança, ou quando ela não quer relatar o nome dele (M elissa). A necessidade de não se reduzir o diagnóstico aos parâmetros físicos aponta para o fato de que avaliar violência sexual é dificílimo (Amália).

$\mathrm{N}$ ão se pode descartar, embora os entrevistados não tenham mencionado, uma certa "invisibilidade" da percepção da ocorrência de abuso sexual por conta de a discussão da sexualidade, em geral, envolver tabus que interditam a sua explicitação.

Os maus-tratos psicológicos, que abrangem rejeição, depreciação, desrespeito, discriminação, punição ou cobrança exageradas (SBP) Fiocruz/MJ, 2001), na fala dos entrevistados, são os que mais apresentam uma certa invisibilidade. A começar pelo fato de, em geral, serem pouco ou nada conceituados. Um profissional desloca o seu conceito para o domínio de uma área específica, entendendo ser um conceito próprio [...] da psicologia (Maurílio). Para os médicos é uma coisa meio difícil [de] lidar (Maíra) com esses maus-tratos, uma vez que o médico também fraqueja por descobrir muitas coisas, um envolvimento emocional [ devido a] não ter preparo, no campo emocional, no campo psicológico (Marina).

Por outro lado, o próprio profissional da saúde mental nem sempre consegue ter visibilidade sobre esse tipo de maus-tratos, por ser difícil [de] identificar isso (Paola) e, por conseqüência disso, há uma necessidade de se definir muito bem o que é violência psicológica, o que é que significa, porque aí tem em diferentes níveis (Pâmela).

Junto a essa dificuldade de se lidar com o conceito de maus-tratos psicológicos, os profissionais se atêm a alguns critérios para sua identificação. Assim, pode existir esse tipo de maus-tratos quando: mãe [...] passa dupla mensagem ( $P$ âmela), ao expressar seu sentimento contrariamente ao que diz; um adolescente se sente coagido de alguma forma (M organa); crianças [são] trancafiadas em casa [ou sofrem] um tipo de tortura (M aurílio); crianças [...] têm medo de sair ( $M$ aíra); a mãe considera a criança [ como se] fosse uma carga nas costas dela [...] não cria um vínculo [...] não procura estimular a criança (Marina).

Por último, outro tipo de ocorrência de maus-tratos mencionado pelos profissionais é a síndrome de "M ünchausen por procuração", definida como a situação na qual a criança étrazida para cuidados médicos devido a sintomas el ou sinais inventados ou provocados pel os seus responsáveis (SBP/Fiocruz/MJ, 2001). Segundo os profissionais são doenças até provocadas por familiares ( $M$ aurílio), que às vezes podem ocorrer quando uma mãe [...] submete a criança a vários exames o tempo inteiro (Paola). Esse tipo de ocorrência de maus-tratos, de um lado, pode se apresentar como algo invisível por ser difícil você chegar a esse diagnóstico [...] porque você fica tentando montar uma síndrome clínica [...] quando às vezes o mal está sendo provocado (Maurílio). Por outro lado, na fala de outro profissional, essa síndrome assume uma certa visibilidade, uma vez que conseguiu identificar dois casos, a partir do fato de sentir, perceber a situação [...] principalmente [quando] há uma relação difícil entrea mãee criança ou uma história mirabolante que a mãe conta [que] não é compatível [ com o estado da criança] (Marina).

0 diagnóstico dos maus-tratos não é uma tarefa fácil. Ferreira e colaboradores (1999) , que analisam a experiência de um serviço estruturado para o atendimento de casos de violência, observam que há dificuldades em diagnosticar tais casos quando mencionam que a equipe desse serviço nem sempre tem clareza para definir quem é a sua clientela.

$\mathrm{Na}$ direção de se conseguir uma maior visibilidade nos casos de maus- tratos, algumas iniciativas no campo da saúde vêm sendo promovidas. A exemplo disso, pode ser citado um guia específico para orientar pediatras e outros profissionais de saúde (SBP/Fiocruz/MJ, 2001) quanto ao diagnóstico e encaminhamento desses casos. Esse guia, de uma certa forma, corrobora a fala dos entrevistados deste estudo quando aponta a negligência como um caso freqüente. Por outro lado, se for possível socializar as informações desse documento e articular tais conhecimentos às práticas, no âmbito dos serviços de saúde, talvez seja possível se demarcar melhor os maus- tratos e a eles se dedicar um tratamento específico.

No balanço da visibilidade e da invisibilidade que os diferentes tipos de maus-tratos assumem no cotidiano dos profissionais, aspectos sociais surgem ou como cenário para se explicar a ocorrência dos maus- tratos ou de forma a concorrer para a dificuldade de se diagnosticar o problema, particularmente nos casos de negligência.

A fala de uma entrevistada é bastante elucidativa para trazer o cenário onde se gesta a violência. Diz ela que, devido a uma mãe ser agredida [pela falta de condições socioeconômicas], 
conseqüentemente [acaba] maltratando o [seu] filho (Priscila). Outra entrevistada sugere que si tuações de vida muitíssi mo precárias [...] levam a uma série de coisas [situações de maustratos] (Paola). Assim, no senso comum, seriam pais que "apanham" da vida e acabam "batendo" nos filhos.

Saindo da perspectiva socioeconômica e se deslocando para a dimensão sociocultural, um profissional chama atenção para o caso de envolvimento de adolescentes em relações sexuais com pessoas mais velhas, que em si se constitui crime, mas que pode ser explicado por se viver num mundo [...] que [...] tem um apelo sexual muito forte, [com] o início da atividade sexual muito cedo e com isso esse argumento da questão legal praticamente não existe (M oacir).

Os aspectos sociais, segundo a ótica dos entrevistados, concorrem de forma decisiva para configurar um quadro de abandono das crianças e dos adolescentes por parte dos pais. Nesse sentido, o país não consegue dar alternativas [...] para as pessoas [ fazendo com que pais não tenham] proteção social nenhuma (M agno) e assim não consigam cuidar de seus filhos adequadamente. Entretanto, mudar isso édifícil [...] tinha que mudar a estrutura social (Élida).

Esses aspectos podem atenuar o fato de se imputar aos pais o papel de alguém que abandona ou não cuida, mas, por outro lado, não diminui a vivência de a criança estar sendo maltratada. Isso pode ser exemplificado nos casos de pais que não visitam seus filhos, [ficam] sem telefonar [...] a questão social aí tem um pe so muito grande, mas a gente considera maustratos também (M eireles). Frente a essas situações, até que ponto um abandono pode ser diagnosticado totalmente como negligência?

A questão de não ver os diferentes tipos de maus-tratos pode também, segundo um profissional, ocorrer pela omissão associada ao medo. $\mathrm{Na}$ fala desse entrevistado, somos muito omissos em relação a isso [...] porque [...] nós temos medo até de nos envolvermos demais com o problema [...] éum pouco de defesa (M agno).

Associada ou não à questão do medo, também pode ser destacada, a partir dos depoimentos, uma certa dificuldade por parte dos profissionais, relacionada à insegurança emocional. Segundo uma médica, tem limite sim [...] principalmente essas questões emocionais, porque eu sei que eu tenho limites [...] (Morgana). Seguindo essa linha de raciocínio, outra médica, referindo-se aos maus-tratos, diz que isso de uma certa forma mexe um pouco comigo
[...] (M aíra). Essa possível insegurança emocional pode ocorrer por conta de não haver um preparo específico na formação médica para a abordagem do problema. Por outro lado, não pode ser descartada a dificuldade para se lidar com essa questão devido a aspectos de ordem subjetiva, tais como: tipos de personalidade, história de vida e defesas psicológicas.

No conjunto das explicações da invisibilidade dos maus-tratos cometidos contra crianças eadolescentes, destacam-se problemas relacionados à formação profissional, principalmente no que tange aos médicos e às enfermeiras. Esses profissionais, em geral, não receberam nenhum tipo de informação específica [ sobre os maus-tratos] (Ednéa) porque a formação era muito pragmática [voltada para o] patológico [no sentido de] reconhecer a doença e pronto (M eireles).

Essa lacuna na formação costuma ser preenchida pela construção de um conhecimento que depende da informação de cada um, do interesse de cada um pelo assunto [e pela] troca com os colegas que [...] já viveram situações se melhantes (Maurílio). Assim, o profissional se caracteriza como alguém autodidata ( $M$ agno) nesse campo.

$\mathrm{Na}$ literatura internacional, a exemplo de Besharov (1993), vem sendo destacado que a não-identificação dos casos de maus-tratos e sua conseqüente não-notificação se relacionam à falta de conhecimento por parte dos profissionais em detectar os sintomas. Dentre os maus-tratos, segundo Finkelhor (1993), os de ordem psicológica se apresentam como os mais complexos, havendo uma maior necessidade de se definir o que se entende por esse tipo de ocorrência de maus-tratos. De uma certa forma, nossos entrevistados corroboram essa afirmação.

$\mathrm{Na}$ abordagem dos maus-tratos físicos, a partir da percepção dos entrevistados, não se explicita uma discussão sobre a invisibilidade desses maus-tratos. Um dos motivos dessa invisibilidade estaria associado à reprodução de padrões culturais, em que se aceita a punição física como medida educativa. Acrescenta-se a isso o fato de, como a literatura específica sinaliza, os profissionais relutarem em se envolver no que considerariam "assunto de família" (Gonçalves \& Ferreira, s/d).

Comparando as falas dos entrevistados sobre o visível e o invisível dos casos de maus-tratos contra crianças e adolescentes com um outro estudo realizado na mesma instituição (Braz \& Cardoso, 2000), no decorrer do ano de 1995, 
verifica-se uma certa mudança. Se naquele momento os depoimentos refletiam que os procedimentos de possíveis casos de maus- tratos eram predominantemente voltados para aspectos anátomo-patológicos, no presente estudo observa-se uma certa preocupação em ampliar o olhar do atendimento para se diagnosticar os maus-tratos, ainda que persistam dificuldades nesse campo.

Esse avanço corrobora o pensamento de Deslandes (1994), segundo o qual a identificação dos casos de maus-tratos que chegam aos serviços públicos de saúde é uma realidade possível, desde que fornecidas aos profissionais condi ções instrumentais e esclarecidas suas responsabilidades com essas crianças e adolescentes.

\section{A crença e a descrença na resolubilidade dos casos de maus-tratos}

As falas dos entrevistados, em geral, apontam para o fato de que, suspeitado ou diagnosticado um caso de ocorrência de maus-tratos, há diferentes abordagens para se lidar com o problema. Uma delas aponta que 0 atendimento não se esgota na ação de um só profissional. Assim, trabal ha-se junto com a assistente social ( $\mathrm{M}$ agno) ou se tem uma psicóloga [...] que fica [...] no ambulatório (Morgana) para ajudar na abordagem desses casos. Enfim, a equipe se reúne, tenta abordar os problemas (Élida). Nesse sentido, eles buscam parcerias entre si, independentemente da classe profissional, para diagnosticar, notificar ou dar um atendimento mais imediato.

Junto a essas parcerias, há encaminhamentos para os diferentes setores da instituição. Comumente, encaminha-se para o serviço social, ou para o CO] [serviço de psicologia médica] (Ednéa), os casos de negligência ou maustratos psicológicos, que são resolvidos no interior do instituto.

Especificamente em relação à negligência, há profissionais que procuram dar conta da demanda, atuando com a família no sentido da conscientização [através da] orientação ( M aurílio) quanto a hábitos de higiene, vacinação, visitas regulares ao médico, dentre outros.

Em termos de encaminhamento exterior, 0 que mais se configura é 0 ato de notificar aos Conselhos Tutelares. Todas as notificações de maus-tratos [passam] pela direção do hospital e [...] antes de [se] fazer qualquer coisa nesse sentido [se] chama a família (Amália).
Parece haver uma associação entre o tipo de maus-tratos e o tipo de encaminhamento. Como foi assinalado, nos casos de negligência, que não envolvem abandono, a abordagem se circunscreve ao próprio instituo. Já os maus-tratos físicos e o abuso sexual, rotineiramente, são encaminhados para os conselhos tutelares. Ainda no que se refere a abuso sexual, há um profissional que real iza encaminhamentos internos e externos, simultaneamente, encaminhando para setores de psi cologia, assistente social [...] para o Conselho Tutelar, tudo que é di reito [solicitando inclusive] o retorno da criança ( $M$ aíra) para assegurar um acompanhamento dos casos.

Como saldo de todas as questões relacionadas ao encaminhamento, tem-se um misto de crenças e descrenças. Crenças quando os profissi onais vêem uma possibilidade de eles mesmos poderem fazer al guma coisa e descrenças frente à não-resolubilidade dos casos. Internamente, nem sempre os profissionais conseguem dar conta de todas as demandas e percebem que há dificuldades de contemplar a complexidade dos casos. No que se juntam para resolver essas questões, nem sempre conseguem êxito, por haver uma "falta de comunicação muito grande" (Paola) de um profissional ter dificuldade [em explicar deforma] que o [outro] profissional entenda (Amália).

Externamente, as ações de encaminhamento aos Conselhos Tutelares são perpassadas pela descrença quanto à obtenção de uma efetiva resolução dos problemas. Como diz um profissional, sou muito descrente [...] tenho uma péssima experiência [...] de notificar ao Conselho Tutelar e eles [conselheiros] fazerem alguma coisa efetiva (M eireles).

Há uma expectativa por parte dos profissi onais em ter retorno das notificações aos conselhos, que segundo um profissional: nunca tive (M oacir) e quando se tem há uma demora para ter uma resposta [trazendo] bastante dificuldade de acompanhar [o caso] (M arina). A competência dos consel hos para resolver esses problemas também é questionada: é cobrado dos profissionais que eles encaminhem [...] M as [...] até onde vai essa competência do conselho para ser o intermediador dessa pessoa [que émaltratada] com uma instância superior? (Amanda). Em outra situação, o procedimento do conseIho é questionado por não ter ouvido uma adolescente que era trancada em casa pela mãe, embora tenha sido solicitado que a chamassem (M organa). Assim, o procedimento baseou-se apenas na versão da mãe. Esses eventos fazem 
com quea parceria mesmo junto ao Conselho Tute lar [seja] difícil (Paola).

Em termos de encaminhamento para setores externos ao serviço estudado, observa-se que, nos casos de negligência, al guns profissionais não utilizam tal procedimento porque acreditam que eles próprios, de uma certa forma, podem resolver 0 problema. Estudos revisados sobre 0 assunto reforçam esse dado (D elaronde et al., 2000; Gonçalves $\&$ Ferreira, s/d), indicando a crença dos profissionais de que eles podem melhor lidar com essa problemática do que os órgãos responsáveis em atender e acompanhar os casos de maus-tratos.

De certa forma, esse não-encaminhamento também sinaliza uma desconfiança em relação a esses órgãos. Na literatura, a exemplo de D elaronde e colaboradores (2000), observa-se que alguns profissionais preferem não notificar por acreditarem que tal procedimento pode produzir efeitos negativos para a vítima.

A descrença em relação à resolubilidade por parte dos profissionais também reflete questões estruturais mais amplas. Gomes (1998), em um estudo sobre denúncia e impunidade em relação à violência cometida contra crianças e adolescentes, faz uma reflexão questionando que, diante desses casos, o aparelho público se apresenta pouco estruturado, tanto em termos numéricos para dar conta de suas demandas quanto qual itativamente no sentido de ter uma abordagem adequada para esses casos.

Para além da descrença quanto à resolubilidade dos casos por parte dos conselhos, a notificação por vezes não é feita por conta do medo de sofrer represálias. Sobre isso, há o caso de um pai que maltrata, que supostamente está envolvido com 0 tráfico [e] ele tem meios de saber [...] quem foi que notificou [...] e se tiver uma represália? (Amália). 0 depoimento ilustra o fato de os profissionais, ao terem que notificar, se sentirem, em al gumas situações, ameaçados em sua integridade física.

Esse sentimento de ameaça é comum nessas situações. Deslandes (1999) faz uma reflexão sobre a notificação de casos de violência por parte de profissionais de saúde. A autora destaca que, dentre as resistências para se notificar tais casos, costuma haver uma experiência negativa por parte desses profissionais em se sentirem perseguidos pelos familiares das vítimas notificadas.

No balanço das crenças e descrenças sobrea resolubilidade dos casos de maus-tratos, tomando como referência o estudo já citado ( $B r a z \&$ Cardoso, 2000), verifica-se que os profissionais da instituição estudada apresentam uma mudança quanto às suas ações. No referido estudo predominou uma certa imobilidade dos profissionais frente à busca de so- luções para o problema. Já no presente estudo se percebe um movimento em direção à discussão e efetivação de procedimentos de diagnóstico e encaminhamento dos casos.

\section{Conclusão}

A análise da percepção dos profissionais estudados sobre critérios, limites e possíveis lacunas na abordagem dos casos de maus-tratos cometidos contra a criança e 0 adolescente, em geral, revela um certo despreparo em relação à temática, embora tenha havido um avanço nos últimos anos. Esse despreparo, por sua vez, pode comprometer a identificação de tais casos e um encaminhamento adequado. Gonçalves e Ferreira $(\mathrm{s} / \mathrm{d})$ observam que um dos entraves à identificação e notificação dos maus-tratos relaciona-se à falta de informações básicas que os profissionais dispõem para realizar um diagnóstico diferencial, ressaltando que tal questão não é contemplada na maioria dos currículos de graduação.

Para solucionar esse entrave, dentre outras ações, faz-se necessário que os serviços compostos de profissionais, cuja formação se centra no modelo biomédico, reflitam sobre alternativas para suprir as lacunas de formação no sentido de se lidar com a complexidade da violência. É nessa perspectiva que se considera a elaboração de protocolos de atendimento. Tal elaboração tanto pode ser entendida como resultado de um amadurecimento de uma equipe capacitada, como pode servir de ponto de partida para essa capacitação.

Por outro lado, uma identificação e um encaminhamento adequado dos casos podem ser perpassados por aspectos emocionais que comprometem uma melhor atuação do profissional frente ao problema em questão. Esses aspectos não dizem respeito necessariamente a "desequilíbrios" pessoais. Podem se referir, dentre outras questões, a dificuldades de lidar com problemas relacionados a tabus e a atitudes de fuga frente a situações estressantes. No sentido de minimizar esses aspectos, os serviços poderiam criar redes de apoio e/ou equipes interdisciplinares para dar suporte ou subsídios às ações dos profissionais.

Assim, a complexidade dos casos de violência demanda articulações entre diferentes perspectivas disciplinares, bem como diferentes ações institucionais. Dessa forma, promover um movimento efetivo onde o "dentro" de uma 
instituição, que depen de de abordagens diferenciadas e imbricadas, se desloca para o "fora", ou seja, para o conjunto das ações públicas, é um desafio para a resolubilidade dos problemas.

Por último, ressalta-se que por mais que o questionamento sobre a eficácia do aparelho estatal seja pertinente, não se pode descartar que um profissional deve ser, antes de tudo, um cidadão. Logo, para que as condições estruturais sejam conseguidas, é importante que as ações profissionais não se restrinjam aos campos disciplinares. É preciso que tais ações se espalhem no espaço público para que consigam não só se conectar com a realidade como também nela intervir.

\section{Referências bibliográficas}

Bardin L 1979. Análise de conteúdo. Edições 70, Lisboa, 229pp.

Becker HS 1993. M étodos de pesquisa em ciências sociais. Editora Hucitec, São Paulo, 178pp.

Besharov DJ 1993. Overreporting and underreporting are twin problems, pp. 257-272. In RJ Gelles, DR Loseke (eds.). Current controversies on family violence. Sage Publications, Newbury Park.

Brasil 1997. Estatuto da Criança e do Adolescente. M inistério da Justiça, Brasília, 110pp.

Braz M \& Cardoso M HCA 2000. Em contato com a violência - os profissionais de saúde e seus pacientes vítimas de maus-tratos. Revista Latino-Americana deEnfermagem 8(1):91-97.

Delaronde S, King G, Bendel R \& Reece R 2000. Opinions among mandated reporters toward child maltreatment reporting policies. Child abuse \& neglect 24(7): 901-910.

Deslandes SF 1994. Prevenir a violência: um desafio para profissionais de saúde. Fiocruz/ENSP/Claves, Rio de Janeiro, 39pp.

Deslandes SF 1999. 0 atendimento às vítimas de violência na emergência: 'prevenção numa hora dessas? 'Ciência \& Saúde Coletiva 4(1):81-94

Ferreira AL, Gonçalves HS, M arques MJV \& M oraes SRS 1999. A prevenção da violência contra a criança na experiência do Ambulatório de Atendimento à Família: entraves e possibilidades de atuação. Ciência \& Saúde Coletiva 4(1):123-130.

Finkelhor D 1993. The main problem is still underreporting, not overreporting, pp. 273-287. In RJ Gelles, DR Loseke (eds.). Current controversies on family violence. Sage Publications, N ewbury Park.

Gomes R 1998. Da denúncia à impunidade: um estudo sobre a morbi-mortalidade de crianças vítimas de violência. Cadernos de Saúde Pública 14(2):301-311.

Gomes R 2001. A análise de dados em pesquisa qualitativa, pp. 67-80. In M CS M inayo (org.). Pesquisa social: teoria, método e criatividade. Editora Vozes, Petrópolis.

Gonçalves HS \& Ferreira AL s/d. A notificação da violência intrafamiliar contra crianças e adolescentes por profissionais de saúde. Instituto de Puericultura e Pediatria M artagão Gesteira/Universidade Federal do Rio de Janeiro [mimeo].

Minayo M CS 1992. 0 desafio do conhecimento. Editora Hucitec-Editora Abrasco, São Paulo-Rio de Janeiro, 269pp.

SBP/Fiocruz/MJ 2001 - Sociedade Brasileira de Pediatria/ Fundação Oswaldo Cruz/M inistério da Justiça, s/d. Guia de atuação frente a maus-tratos na infância e na adolescência, 40pp.

Artigo apresentado em 12/10/2001 Versão final apresentada em 5/1/2002 Aprovado em 10/2/2002 